\title{
Lope de Vega, Poeta Lírico
}

\author{
POr JOSÉ JIMÉNEZ BORJA
}

El hecho frecuente en las grandes producciones literarias de concentrar tanto prestigio sobre sí que atenúa el de las obras del mismo autor, se repite en Lope de Vega. La obra dramática es la que le valió los títulos de Fénix de los Ingenios y Monstruo de la Naturaleza, la que le dio la fama de equiparar todo lo excelente y grandioso del mundo con la calidad de su escena, la que hizo consternación nacional su muerte y congoja pública del pueblo de Madrid su entierro en el verano de 1635. Quedaron iluminados por una luz vacilante' y casi defectible sus otros grandes valores: el del poeta lírico, épico, didáctico y burlesco, el del novelista, crítico, historiador y maestro de la acción en prosa. Ha sido el análisis persistente de todos estos relieves, desde fines del siglo pasado, el que nos hace asistir a las célebraciones del Cuarto Centenario, con una visión más equilibrada del portentoso escritor aunque dicho análisis na rebase todavía los sectores especializados. Rècordemos ahora solamente la voz matinal, llena de garbo y dulzura, del poeta intimista.

Lope de Vega fue un grande y desbordado poeta lírico. No sólo creó páginas inmortales dentro de las fronteras del género, sino que salpicó todas sus comedias, poemas épicos y relatos en prosa de emociones subjetivas que se desprenden del contexto y que pueden formar, con plena autonomía, desde simples letrillas o epigramas hasta verdaderas odas de inspiración pindárica o anacreóntica.

¿Fue más grande poeta lírico o dramático? No discutamos el cetro de su riqueza, variedad y fecundidad en el teatro, pero elevemos hasta ese mismo nivel, o hasta uno muy próximo, sus expresiones de sentimiento personal, alado y fino, pues solamente aquí es verdad lo que dice: "Yo como los ruiseñores, tengo más voz que carne", 
Desde luego la crítica alemana, especialmente con Vossler, señala el lirismo de Lope como la única frecuencia genuina de su ser sobre el estilo literario. Su conducta vital sigue una línea de repre. sión en todo lo que no es propiamente lírico. Para ganarse el pan de cada día este hombre de temperamento cálido e irruptor, es secretario de nobles -el marqués de Sarria, el duque de Sessa, el duque de Alba-y se ve obligado a constreñir su efervescencia interior en el estilo cortesano de las cartas y en el estila cortesano de sus madrigales mitológicos, juegos de sociedad, parabienes lisonjeros y demás poesías de encargo. Literatura sometida y doméstica, retoricismo hinchado, aunque con el sello de su buen gusto, el soplo de su lozanía y, aquí y allá, la eflorescencia de notas interiores, como escapadas de un hondo substracto. La obra dramática, pese a toda su grandeza y sensibilidad, también es de compromiso, compromiso ya no con sus notables protectores, sino con las turbas que llenaban los corrales donde se representaban sus comedias. En este sentido sigue siendo secretario aunque el generoso déspota cambie de figura. Es el secretario del pueblo español que quiere que le exalten su vieja epopeya, que le repasen sus ideales de honra, que lo adormezzan con sus sueños de esplendor nacional. Lope se ajusta a esta exigencia y sólo en el límite juega su iniciativa creadora.

La lírica es por lo tanto su instrumento y su campo de liberación, descontado aquel lirismo que cae dentro de sus obligaciones cortesanas como la mayor parte del contenido en la Arcadia, novela pastoril en prosa y verso, juzgada como la mejor del género en España, por su movimiento delicioso $\gamma \mid$ lgentihiperooque en el fondo sólo es una amenidad reverente para encantar al joven duque de Alba, a su madre y demás cortesanas a los cuales se descubre, dentro del sistema de clave, bajo sus disfraces de pastores. De otro lado se ha sostenido que la lírica de Lope, como lo más feliz de sus otras obras no teatrales, está transida de emoción dramática y que vendría a ser un eco próximo o lejano de aquella, deshielo involuntario de esas altas cumbres. Es que la escena y en particular la escena española, se adaptaba mejor a su idiosincracia esencialmente unida al espíritu multitudinario, a la vista y el oído universales, ante los cuales gustaba desplegar su fuerza comunicativa, su virtuosismo de exhibición y gracia exteriores. Su lirismo es por eso también en parte dramático sin que sea subsidiario ni aun en el caso de composiciones desprendidas de sus comedias.

- Resaltaré las principales cualidades de su obra lírica, al mismo tiempo delicadamente espiritual y sanguinea, contradictoria en sus 
pasiones raigales como la vida y la muerte, la luz y la sombra, el tiempo y la eternidad, que el poeta trata de juntar en una crispación de sus manos barrocas.

Es Lope, en primer término, un poeta esencialmente humano. En vida demostró ser un ente solidario, piadoso con el dolor ajeno, amable, ganoso de paz y amistad. Feliz porque Góngora le había extendido una vez la mano, en carta al duque de Sessa manifiesta su esperanza de haberle parecido "un hombre de bien". Su poesía no se eleva nunca, en consecuencia, del habitat en que discurre el hombre. Quiero decir con ello que no sobrepasa el realismo geográfico sino hasta un segundo plano en que sus figuras se idealizan mediante los arquetipos neo-platónicos. No pasa al tercer plano del arte deshumanizado de Góngora. Sus mujeres, en aquel segundo plano, ya no son Elena Osorio, Micaela Luján o Marta de Nevares, sino Filis, Camila Lucinda o Amarilis, están entre jaspes, entre arreboles, sus ojos son luceros, sus manos vuelven oscuras las azucenas, pero son identificables, las reconocemos:

Habló Filis y tuvieron alma de coral sus labios...

Tu conoces, Lucinda, mi firmeza y que es de acero el pensamiento mía.. ...la divina Amarilis, pastora de tiernos años y de pensamientos libres.

El mismo, con plena conciencia y a pesar de su afición culturista, afirmaba que siendós óptima la escuela, su defecto estaba en la exageración y principalmente en la reprensible aventura de "sacar metáforas de metáforas". El desdoblamiento de la imagen gongorina, como la ascensión de la metáfora ordinaria que constituye lo normal, la metáfora lexicalizada que dice Dámaso Alonso, a la melófora de atrevido arranque propulsando la materia poética a una esfera desconocida hasta entonces como la descripción de la ninfa hija de Doris en el Poliffemo:

Galatea es su nombre y dulce en ella el terno Venus de sus Gracias suma; son una y otra luminosa estrella lucientes ojos de su blanca pluma...

El carácter amistoso y expresivo de Lope también estaba opuesto en lo terreno al carácter hosco y concentrado de Góngora. 
El uno tenía bastante con verterse sobre una realidad idealizada; el otro, partiendo de esta, que ya la consideraba rutinaria, volabo al ámbito de la poesía pura, del mundo audaz y prístino.

Es poeta natural. Natural en su maravilloso equilibrio psicosomático, en su amor a todo lo viviente, en su fluencia espontánea, por rebosamiento inextinguible y fácil. No es naturcrlista con el estremecimiento de Pousseau que cree ver en cada brizna la palpitación del alma universal. Es naturalista por fraternidad ingenua con las cosas y por la selección de las más bellas -rostros de mujer y rostros del paisaje- " a la manera de su poeta preferido Garcilaso. Eștci naturalidad está patente en sus Epístolas donde con el decoro y la gracia que le son inseparables cuenta intimidades de familia en la forma más sincera y candorosa. Ejemplo citado sobre el particular es el de su respuesta a la Amarilis del Perú, aquella que le escribió del "otro mundo" y que despierta en él correspondencia platónica:

Dos veces me casé de cuya empresa sacaréis que acerté, pues porfiaba, que nadie vuelve a ver lo que le pesa. Un hijo tuve en quien mi alma estaba; allá también sabréis por mi alegria que Carlos de mis ojos se llamaba...

De mi vida, Amarilis, os he escrito 10 ique nunca pensé, mirad sì os quiero, pues tantas libertades me permito. "Jorge Puccinelli Converso"

La soltura, el donaire, la persuasión definitiva de este carácter natural se aprecia sobre todo en los romances, en las coplas, en la poesía ligera, donde sus metros cortos parecen arroyuelos frescos, exquisitamente secuentes y cordiales.

Es poeta popular. Su mismo origen de familia, a pesar de sus sueños de nobleza por lo Carpio, su corazón afectuoso, su interés por lo humano, lo hicieron un receptáculo predestinado de la fantasía, de los sentimientos, de las voliciones populares. Recogió cantares y canciones, estas últimas sin el sentido renacentista, sino con el de regocijos para bodas, bautizos, vendimias, para mayo y para San Juan; romances, seguidillas, letras para cantar y para bailar, letras sacras, tréboles, villancicos. Esparció dadivosamente en las comedias estos aires oreantes de la montaña, de la playa y de la campiña y con eso les dio una misteriosa intensidad lírica: 
Velador que el castillo velas, vélale bien y mira por tí, que velando en él me perdí...

(Las Almenas de Toro, Parte XIV)

Blanca me era yo cuando entré en la siega; dióme el sol y ya soy morena...

(El Gran Duque de Moscovia, Parte VII)

A la viña viñadores, que sus frutos amores son; a la viña tan garrida, que sus frutos amores son...

(El Heredero del Cieio, Acad. II)

Este acento popular hace que sea Lope de Vega "quien llega más a los nuevos poetas españoles", al decir de Guillermo DíazPlaja. En particular Federico García Lorca ha recogido tan singular herencia en su lírica y en su teatro. La seguidilla de Lope:

iAy, río de Sevilla,

que bien pareces

lleno de velas blancas

y ramos verdes!

es comparada con la Serrenata de García Lorca:as

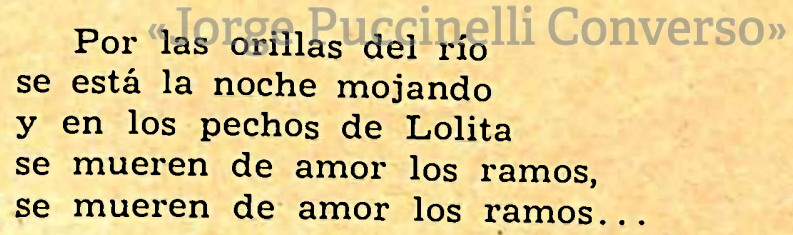

Por "las orillas del rio lli Converso"

se está la noche mojando

y en los pechos de Lolita

se mueren de amor los ramos,

se mueren de amor los ramos...

Es poeta sabio. El popularismo no era lo único ni tampoco lo indomeñable. En su más cálida esencia popular había dos factores cultos: en primer término la selección de los elementos discriminando lo ciertamente elegante de lo grosero o inocuo; y en segundo, el toque de gracia, el hálito recreador sobre la arcilla vulgar, que han reconocido los críticos. No era un extraordinario humanista, pero sí un excelente rethor, de cultura latina desde la infancia, de gran versación preceptiva, de señorío sobre la historia antigua, la mitología, las letras griegas y romanas, la literatura italiana, coetánea o poco anterior, en fin, sobre toda la utilería literaria que necesitaba un gran escritor de su tiempo. A la gran 
manera del Renacimiento escribió sus poemas épicos marciales y religiosos, su novela pastoril, su novela de aventuras, sus sonetos, sus rimas humanas y divinas. En este aspecto su lírica so rozas con el cultismo del cual sólo toma en cierto grado la forma, la maJia vocabular y sinláctica, pero no la subsiancia do la belleza gongorina. Llega al conceptismo por la delgadez y el contraste dis las ideas, pero no capta el reino secreto de la poesía acrisolada.

Es roeta ocasionalmente jocoso. En la Gatomaquia hizo la parodia del roems épico, burlándose del género. Deja en libertad aquí sus grandes cualidades de virtuoso para retozar señorialmente con la batalla de los gatos. Se ha observado, sin embargo, que no llega al humor meditabundo y sombrío de Quevedo.

Es coeta religioso. Sin ser escriturario, ni neo-escolástico, tiene una piedad simple y feryorosa lejos de todo problema especulotivo. La gran corriente mística del pueblo castellano se renueva y estremece con la vitalidad de Lope. Tiene vehemente devoción a Cristo, a la Virgen, a los santos españoles. La crisis interior que io lleva al sacerdocio en 1614, está jalonada de hondas, desgarradas expresiones líricas:

Muere la vida y vivo yo sir: vida ofendiendo la vida de mi muerte; sangre divinadelas venas vierte Y $\mathrm{mi}$ diamante su clureza olyida.

Está la majestad de Dios tendida en una dura cruz y yo de suerte que soy de sus dolores el más fuerte y de su cuerpo la mayor herida...

Su gran afabilidad con todos los seres determina la máxima humanización de las personas divinas. Las trae cerca de sí y las toca, como ha señalado Moniesinos, las toca y acaricia. La Virgen María aparece así como una adolescente mórbida de dulzura y suavidad murillescas:

Zagala divina, bella labradora, boca de rubies, ojos de paloma, santísima virgen, soberana aurora, arco de los cielos y del sol corona... 
Es poeta barroco. Con base en el Renacimiento, que es medida y equilibrio, apresura su ritmo hasta el dinamismo y el tumulto, tal como en cualquier imafronte o retablo limeño de su siglo. Acumula elementos tras elementos y después le resulta un problema difícil conciliarlos. Pero el barroco está unido inseparablemente al espíritu de la Contra-Reforma que tiene propósitos universales y coherencia final. Por lo tanto, Lope, aunque barroco, no es romántico. Sus grandes contradicciones vitales, lo sensual y lo místico, lo popular y lo erudito, lo vulgar y lo coriesano, su arrebato y serenidad, se turnan o se comprometen dentro de marcos tensos pero seguros. Estos mismos choques hubiesen dado lugar en el romanticismo o tremolaciones irresolubles e infinitas.

Es poeta, en fin, de incertidumbres formales en que todo resplandece y late, pero donde no hay nada totalmente facetado y límpido con aquella unicidad luminosa del diamante. Los más bellos poemas, como aquel famoso romance: "A mis soledades voy, de mis soledades vengo..." con un principio maravilloso, se pierden a menudo en desmayos y vaguedades.

Pero a pesar de todo el torrente es insondable y riquísimo. El genio de Lope tuvo en la lírica su efusión más fidedigna y pudo llegar al desengaño flagelante de los poemas de la Dorotea, la acción en prosa incrustada de poesía que se considera su obra más auténtica, personal, depurada y cristalina.

\section{Biblioteca de Letras}

